\title{
COOLING CURVE ANALYSIS IN BINARY Al-Cu ALLOYS: PART I- EFFECT OF COOLING RATE AND COPPER CONTENT ON THE EUTECTIC FORMATION
}

\author{
M. Dehnavi ${ }^{1 *}$, F. Kuhestani ${ }^{2}$, M. Haddad-Sabzevar ${ }^{1}$ \\ ${ }^{1}$ Department of Materials Engineering and Metallurgy, Ferdowsi University of \\ Mashhad, Mashhad, Iran \\ ${ }^{2}$ Faculty of Materials Engineering, Semnan University, Semnan, Iran.
}

Received 28.02.2015

Accepted 25.08.2015

\begin{abstract}
There are many techniques available for investigating the solidification of metals and alloys. In recent years computer-aided cooling curve analysis (CA-CCA) has been used to determine thermo-physical properties of alloys, latent heat and solid fraction. In this study, the effect of cooling rate and copper addition was taken into consideration in non- equilibrium eutectic transformation of binary $\mathrm{Al}-\mathrm{Cu}$ melt via cooling curve analysis. For this purpose, melts with different copper weight percent of 2.2, 3.7 and 4.8 were prepared and cooled in controlled rates of 0.04 and $0.42{ }^{\circ} \mathrm{C} / \mathrm{s}$. Results show that, latent heat of alloy highly depends upon the post- solidification cooling rate and composition. As copper content of alloy and cooling rate increase, achieved nonequilibrium eutectic phase increases that leads to release of high amount of latent heat and appearing of second deviation in cooling curve. This deviation can be seen in first time derivative curve in the form of a definite peak.

Key words: cooling curve, latent heat, first derivative curve, non- equilibrium eutectic

\section{Introduction}

Depending on the casting conditions and alloy composition, microstructure, properties and characteristics of the aluminum alloys will be different [1]. The cooling rate affects the structure of as-cast alloys in a well-established manner, i.e. the grain size, the dendrite arm spacing (DAS) and the size of structure constituents (both primary and eutectic) decrease with increasing the cooling rate [2,3]. Backerud [3], found that $\mathrm{Al}-\mathrm{Cu}$ alloys start to solidify through the development of a dendritic network followed by a eutectic reaction in the interdendritic regions by means of which the eutectic $\mathrm{Al}_{2} \mathrm{Cu}$ is formed in combination with the remaining aluminum. With further decrease in
\end{abstract}

*Corresponding author: M. Dehnavi, Mehdi_6664@yahoo.com 
temperature, the $\mathrm{Al}_{2} \mathrm{Cu}$ phase precipitates from the $\alpha$-phase $[2,4]$. The thermal analysis is widely used in the evaluation of processing of aluminum alloys because it can provide several pieces of information regarding the alloy. Thermal analysis is based on the fact that the thermal events on a heating or cooling curve are directly related to phase transformation occurring in a sample. Many techniques are available to investigate the solidification of metals and alloys. Some of them were standardized such as DTA and DSC. Although these techniques are very accurate and well documented, they are inadequate for industries to investigating solidification of metals and alloys [58]. The other way for investigating solidification of metals and alloys is the cooling curve analysis method. This technique is based on recording and analysis of the temperature versus time data collected during the solidification of the sample. In recent years computer-aided cooling curve analysis (CA-CCA) has been used to determine thermo-physical properties of alloys, latent heat and solid fraction. Being very simple to setup it can be widely used, especially in industries [7-11]. The foremost use of cooling curves has been the determination of arrest points during solidification. Arrest points on cooling curves are related to the precipitation events, as the latent heat of formation is released the cooling is arrested temporality. This method was introduced in 1954 with the work of Morrogn- Williams [12] and Hultgren et al. [13] on cast irons. A 1969 paper by L. Backerud and B. Chalmers, introduced a technique that improves the understanding of the cooling curve method through the use of the time dependant derivative of the cooling curve [14]. The derivative of the cooling curve improves the sensitivity of the measurements and allows for better precision in determining the exact points of primary and eutectic solidification events [15].

\section{Experimental procedure}

Binary Al-Cu alloy with the compositions given in Table 1. was prepared in an electrical resistance furnace from $99.9 \%$ pure aluminium and an $\mathrm{Al}-48 \% \mathrm{Cu}$ master alloy. The chemical composition of the alloy was determined by a spark spectrum analysis. To investigate the effect of cooling rate on the solidification processing, Specimens with dimensions $(\mathrm{D} \times \mathrm{H}) 22 \times 20 \mathrm{~mm}$ and $\sim 10 \mathrm{~g}$ weight were melted inside a DTA furnace in a alumina crucible (Fig. 1). High purity argon gas $(99.999 \%)$ was running throughout the test to reduce the risk of oxidation of the samples. In the all experiments, the samples were heated to $705 \pm 5{ }^{\circ} \mathrm{C}$ and isothermally kept at this temperature for a period of $5 \mathrm{~min}$ in order to stabilize the melt conditions.

Table 1 Chemical composition of the Al-Cu alloys (wt/\%).

\begin{tabular}{llll}
\hline $\mathrm{Cu}$ & $\mathrm{Si}$ & $\mathrm{Fe}$ & $\mathrm{Al}$ \\
\hline 4.8 & 0.05 & 0.06 & $\mathrm{Bal}$ \\
\hline 3.7 & 0.04 & 0.06 & $\mathrm{Bal}$ \\
\hline 2.2 & 0.05 & 0.08 & $\mathrm{Bal}$ \\
\hline
\end{tabular}



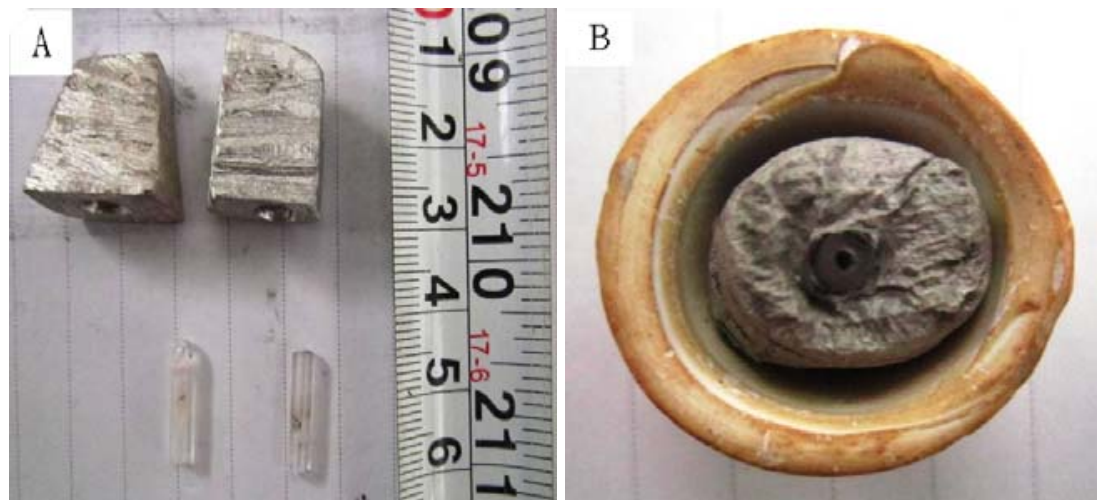

Figure 1. A: Sample and quartz Shield B: Alumina crucible and sample after solidification.

To create of different cooling rates, two experiments were designed as follows: In the first series of experiments the sample was cooled inside the furnace (slow cooling rate $0.04{ }^{\circ} \mathrm{C} / \mathrm{s}$ ). In the second series of experiments, in order to increase the cooling rate, the sample was cooled at outside the furnace to the room temperature (middle cooling rate $0.42{ }^{\circ} \mathrm{C} / \mathrm{s}$ ). The temperature of the samples was recorded by a K-type thermocouple with the wire diameter of $0.15 \mathrm{~mm}$ placed at the center of the sample and an Advantech 4718 data acquisition system connected to a personal computer. In order to assure the good contact between the thermocouple and the melt, quartz sheathed with an external diameter of $2.5 \mathrm{~mm}$ was used [4]. Each trial was repeated three times. The temperature vs. time and first derivative were calculated and plotted. There are different ways to define the cooling rate. In the present research the cooling rate was calculated by dividing the total solidification range $\left(T_{L}-T_{S}\right)$ to the local solidification time according to [15]. Samples for study the microstructure were taken from a location close to the thermocouple tip. After grinding, polishing and etching with $0.5 \%$ HF reagent, the microstructure was examined by a Olympus BX60 optical microscope and LEO 1450VP electron microscopy. Quantitative investigation by SEM images was accomplished using "Clemex Vision" software.

\section{Results and discussion Microstructure}

Fig. 2a, show the dendritic microstructure of the Al-4.8 wt. $\% \mathrm{Cu}$ at $0.42{ }^{\circ} \mathrm{C} / \mathrm{s}$ cooling rate. The microstructure configurations consisted of $\sigma_{A l}$ dendrites and the

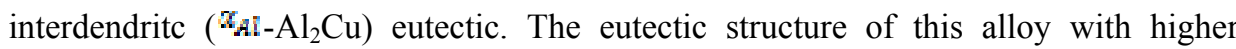
magnification is presented in Fig. 2b. The microstructure configurations for other alloys were similar. By melting and freezing an alloy and registering the temperature-time curves, several characteristic behaviors can be determined [16,17]. 

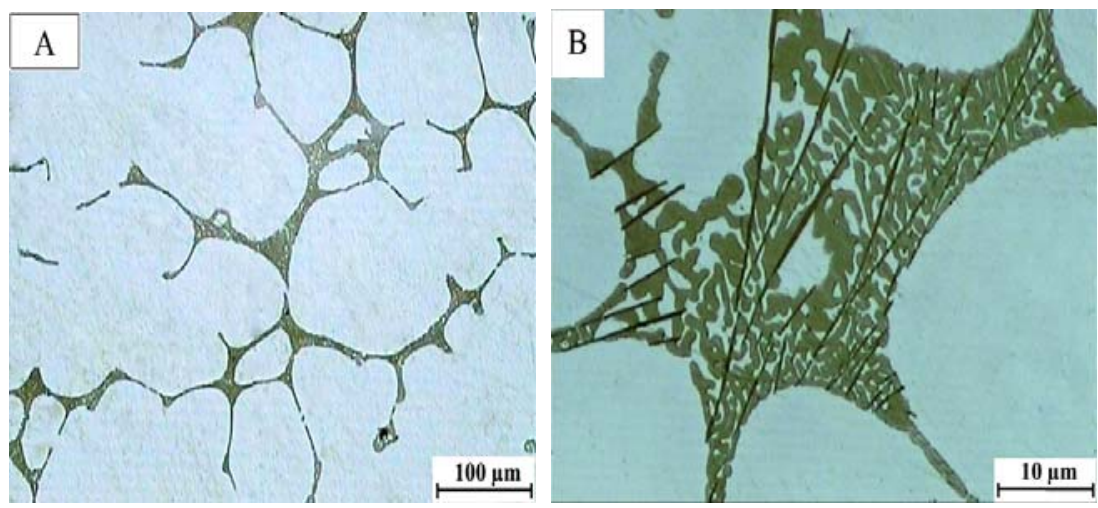

Figure 2. A: Microstructure of Al-4.8 wt.\%Cu at $0.42{ }^{\circ} \mathrm{C} / \mathrm{s}$ cooling rate, B: eutectic structure in higher magnification.

As a cooling curve reflects a balance between the evolution of heat in the sample and the heat flow away from the sample, the start of solidification is easily determined by the latent heat associated to the liquid-solid transformation. Some other variations on the curve can be related to other processes, reactions, and of course the end of solidification [9]. Figure 3a shows cooling curves of all samples in $0.04{ }^{\circ} \mathrm{C} / \mathrm{sec}$ cooling rate. With regard to the type of solidification, it can be seen two deviations in the cooling curves of 3.7 and $4.8 \mathrm{wt} . \%$ alloys which indicates that phase transformation is occured during solidification. First deviation is related to the formation of $\alpha_{A l}$ primary dendrites which is followed with their growth and coarsening, and then, second

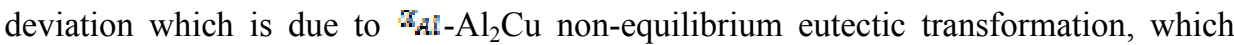
occurs in final stages of solidification. With respect to thermal analysis results, it can be

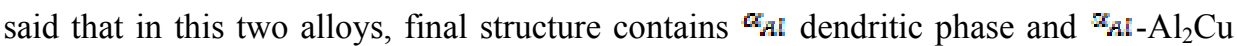
non-equilibrium eutectic [3,4]. However, in this figure and for $2.2 \mathrm{wt} . \%$ alloy, it can be seen that the second deviation is missed in its cooling curve. This topic is more obvious in Fig. $3 b$ which is a part of Fig. 3a cooling curves, which is related to the nonequilibrium eutectic formation zone. With comparison of these curves, it seems that the solidification of $2.2 \mathrm{wt}$ \% alloy is finished in single phase and non-equilibrium eutectic is not formed in this alloy.

But as in Fig. 4 the electron microscopy images shows, for all alloys, in both cooling rates, non-equilibrium eutectic is formed during solidification. Whereas $2.2 \mathrm{wt}$. $\%$ alloy cooling curve in $0.04{ }^{\circ} \mathrm{C} / \mathrm{s}$ cooling rate, doesn't show this point. In this images, the dark regions are $\sigma_{A l}$ phase and the light regions are non-equilibrium second phase which forms non-equilibrium eutectic with residual melt in final stages of solidification. For a better investigation of occurred phase transformations during solidification by thermal analysis of cooling curves, plots of first derivative curves versus time for all alloys in both cooling rates is used. As mentioned in introduction section, first derivative curves shows the instant changes of alloy cooling rate, actually which is more sensitive in occurred phase transformation during solidification than basic cooling curves. 

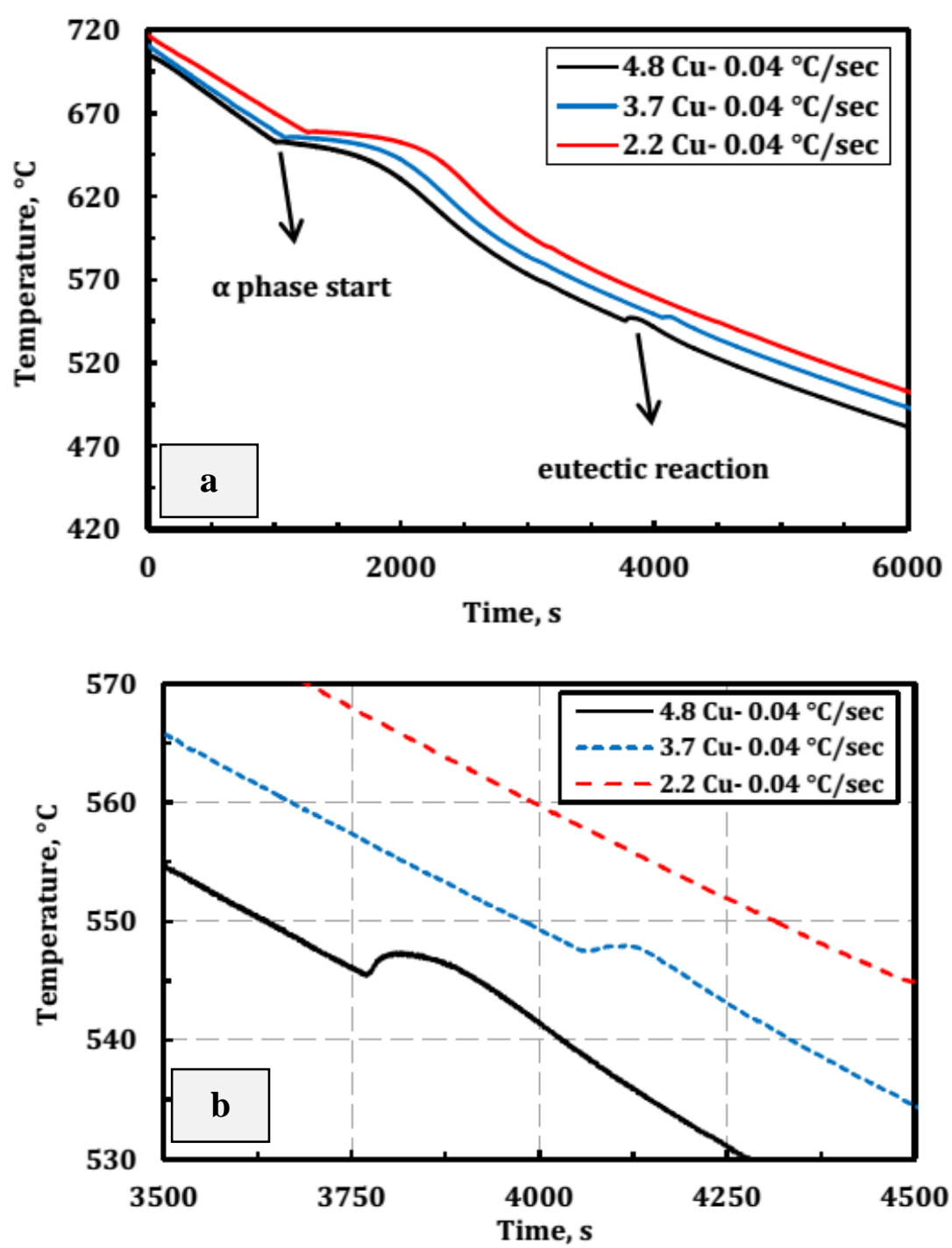

Figure 3. Temperature vs. time cooling curves recorded for different alloys at constant cooling rate.

Figures 5 and 6 shows the cooling curve with first derivative curve for 3.7 and 4.8 wt. $\%$ alloys in $0.04{ }^{\circ} \mathrm{C} / \mathrm{s}$ cooling rate. As can be seen, phase transformations which are determined by deviations in cooling curves are seen by completely distinct peaks in derivative - time curve. With respect to derivative curves, three peaks are distinct, which indicates three phase transformations is occurred during solidification, while main cooling curves indicated only two phase transformations for this alloys. First peak is

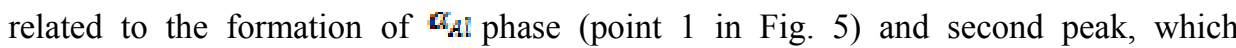
occurred before eutectic transformation, is related to the formation of series of needle- 
like iron intermetallic compounds which is not observed in the main cooling curve (point 2 in Fig. 5). This compounds un-dissolution in melt, in final stages of solidification, precipitate on the eutectic compound usually [18]. In this figures, third peak is related to the formation of non-equilibrium eutectic transformation (poin 3 in Fig. 5).

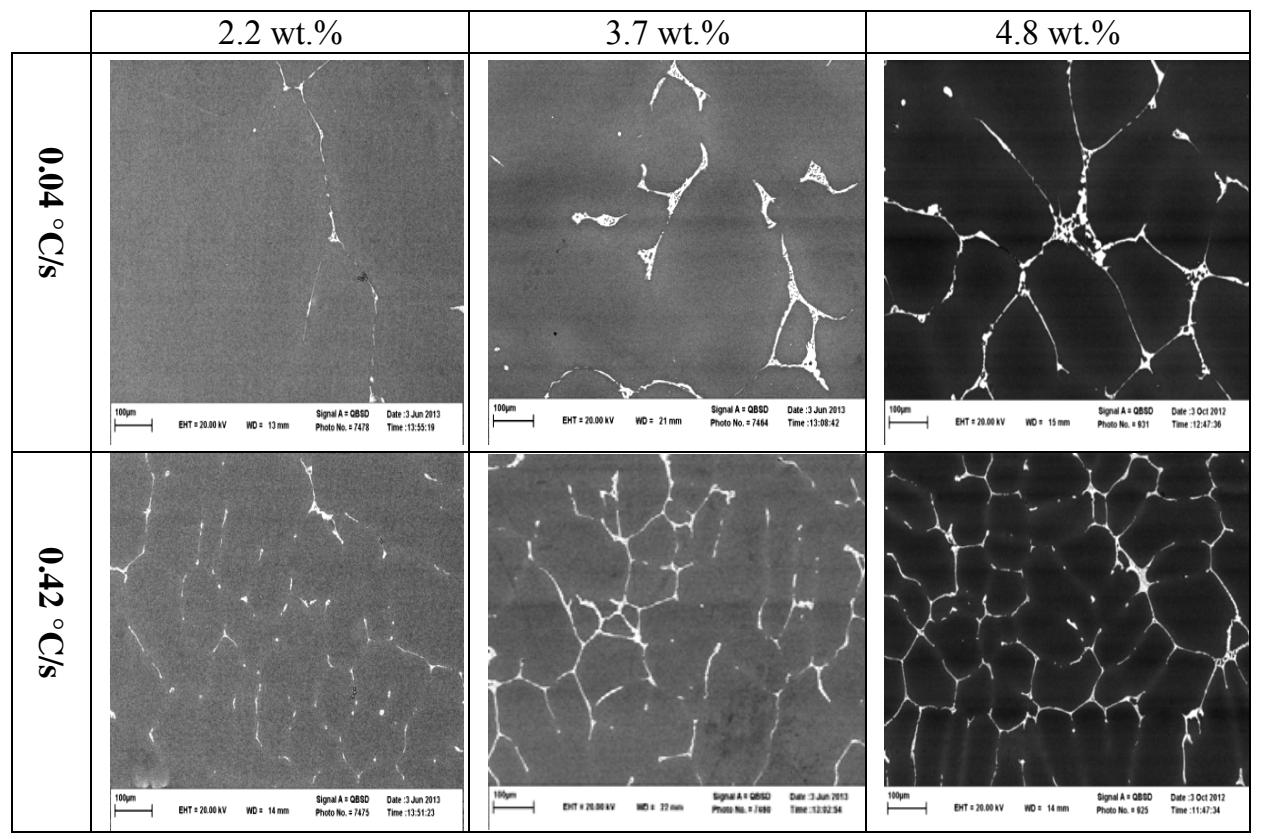

Figure 4. BSE migrographs of alloys at different cooling rates.

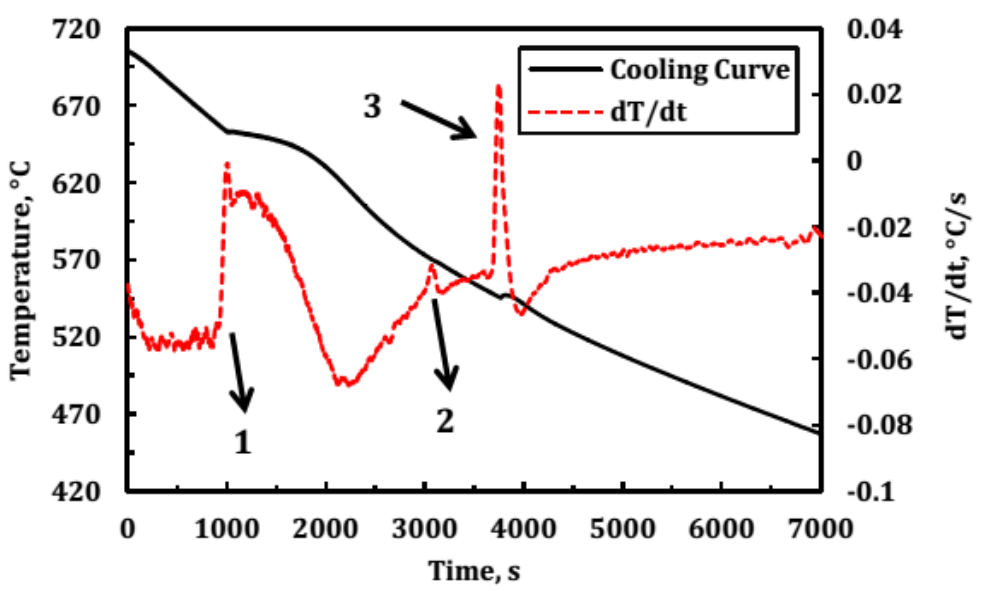

Figure 5. Cooling curve and first derivative curve of Al-4.8 wt.\%Cu at $0.04{ }^{\circ} \mathrm{C} / \mathrm{s}$ cooling rate. 


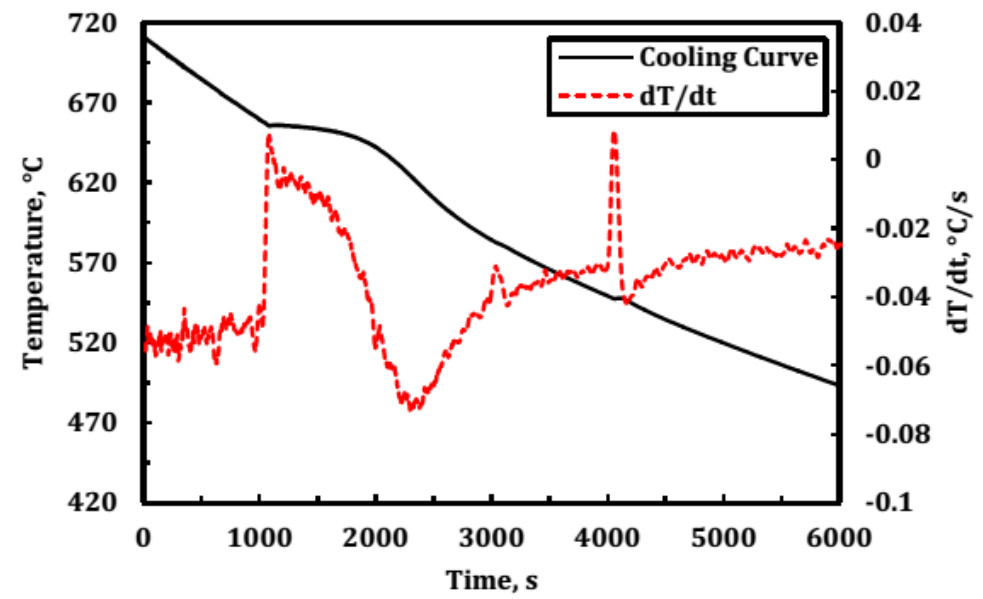

Figure 6. Cooling curve and first derivative curve of Al-3.7 wt.\%Cu at $0.04{ }^{\circ} \mathrm{C} / \mathrm{s}$ cooling rate.

Figure 7 shows the EDS analysis of needle-like blades of 3.7 wt.\% alloy. Figure 8 shows the 2.2 wt. \% alloy cooling curve with its first derivative curve in $0.04{ }^{\circ} \mathrm{C} / \mathrm{s}$ cooling rate. It is investigated before that cooling curve is not sufficient for describing the solidification behavior of this alloy and plotting the first derivative - time curve seems to be necessary. As the derivative - time curve indicates, during solidification of this alloy, like other two alloys, non-equilibrium eutectic transformation is occurred while this transformation is not observed in cooling curve. Although the cooling curve is same in this three alloys, but the most important reason for this problem can be related to lower copper content and so lower latent heat loose than other two alloys.
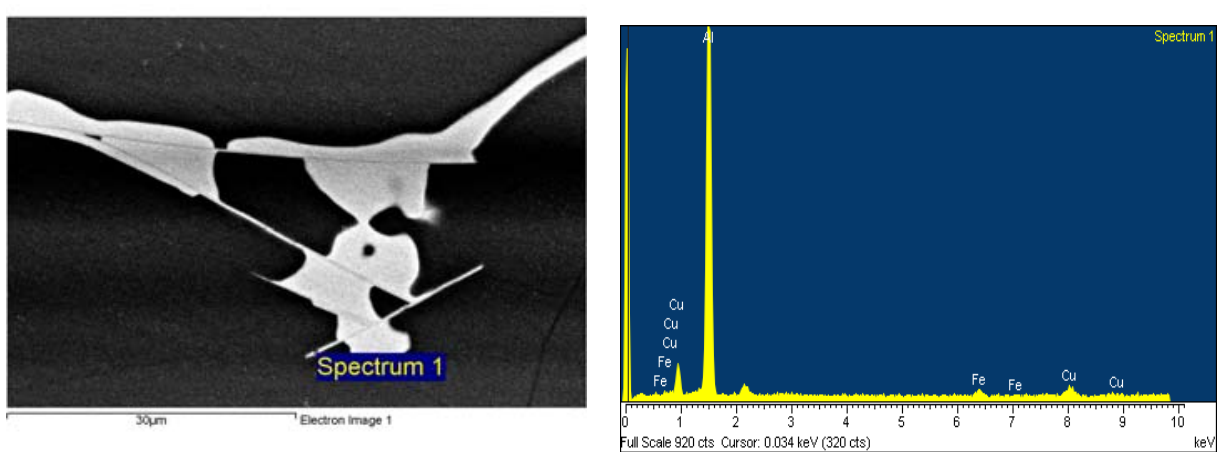

Figure 7. SEM image with EDS result of Fe-riched phase. 


\section{The effect of latent heat on the shape of cooling and derivative curves.}

The effect of cooling rate

As investigated in the introduction section, solidification parameters can be calculated by cooling curve at different cooling conditions. The metallurgical reactions that have enough latent heat can be detected by this curve [16]. Although some reactions do not release enough latent heat to be recognized by the cooling curve, the first derivative of the cooling curve gives more details about these reactions [11].

Figure 9. shows the cooling curve with first derivative curve of $2.2 \mathrm{wt} . \%$ alloy in $0.42{ }^{\circ} \mathrm{C} / \mathrm{s}$ cooling rate. With a comparison of Figs 8 and 9 it can be seen that with respect to variation of cooling rate from 0.04 to $0.42{ }^{\circ} \mathrm{C} / \mathrm{s}$, second deviation is created in cooling curve while in $0.04{ }^{\circ} \mathrm{C} / \mathrm{s}$ cooling rate, only one deviation seen in cooling curve. Most important reason for this difference is related to non-equilibrium eutectic amount increment with increase in cooling rate. The amount of non-equilibrium eutectic formed in investigated alloys, is dependent to the cooling rate and copper content in primary composition of alloys two factors which previous investigation results shows that the amount of non-equilibrium eutectic, increases with increment of cooling rate and copper content and the variation of non-equilibrium eutectic amount is more dependent to composition variation (copper content) [17]. Table 2. shows the quantification results of non-equilibrium eutectic amount.

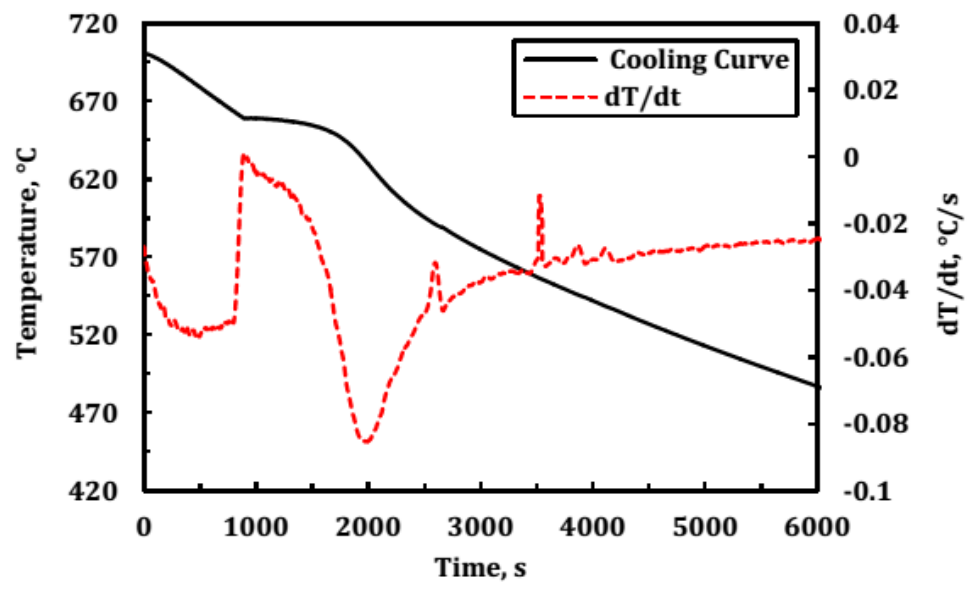

Figure 8. Cooling curve and first derivative curve of Al-2.2 wt.\%Cu at $0.04{ }^{\circ} \mathrm{C} / \mathrm{s}$ cooling rate. 


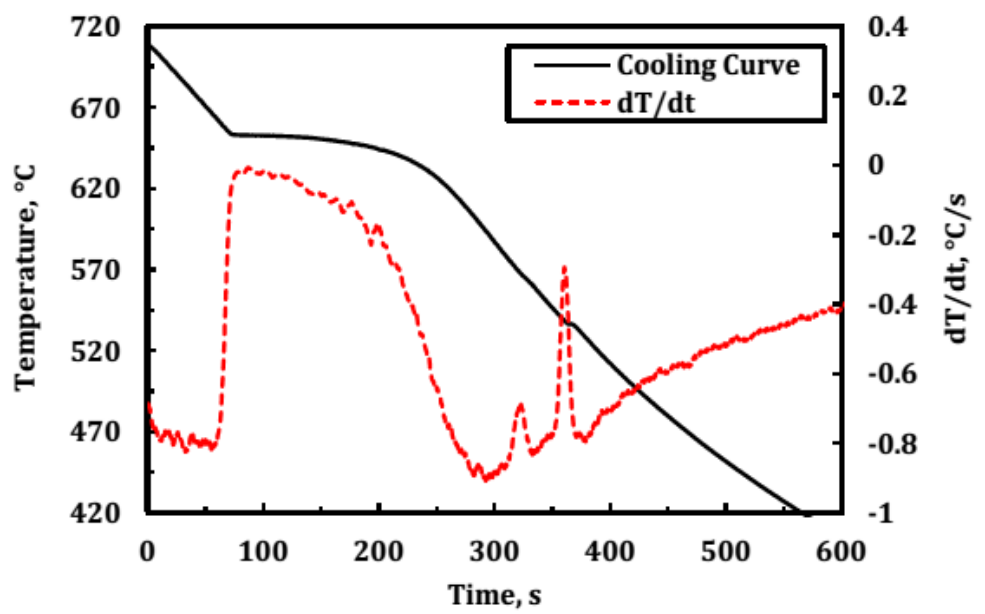

Figure 9. Cooling curve and first derivative curve of Al-2.2 wt.\%Cu at $0.42{ }^{\circ} \mathrm{C} / \mathrm{s}$ cooling rate.

Table 2 Effect of cooling rate and composition on the amount of non-equilibruim eutectic.

\begin{tabular}{ccc}
\hline $\begin{array}{c}\text { Alloy name } \\
(\mathrm{wt} / \% \mathrm{Cu})\end{array}$ & $\begin{array}{c}\text { Cooling rate } \\
\left({ }^{\circ} \mathrm{C} / \mathrm{s}\right)\end{array}$ & $\begin{array}{c}\text { non-equilibruim } \\
\text { eutectic }(\mathrm{wt} / \%) .\end{array}$ \\
\hline 2.2 & 0.04 & 2.3 \\
& 0.42 & 2.9 \\
\hline 3.7 & 0.04 & 4.2 \\
& 0.42 & 4.6 \\
\hline 4.8 & 0.04 & 5.1 \\
& 0.42 & 5.7 \\
\hline
\end{tabular}

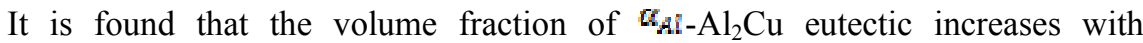
increasing cooling rate. In $0.04{ }^{\circ} \mathrm{C} / \mathrm{s}$ cooling rate, due to slow-footedness of cooling rate, the amount of non-equilibrium eutectic formed in final structure will be too low; so the amount of loosed latent heat is very low, so it doesn't cause recognizable change in main cooling curve. But with cooling rate increment to $0.42{ }^{\circ} \mathrm{C} / \mathrm{s}$ the amount of nonequilibrium eutectic also increases which increases the solidification latent heat. The intensity of this increment is too much that results the second deviation in the cooling curve.

Chemical composition effect

With further comparison of Fig. 3b curves, it can be find out that why in a constant cooling rate, second deviation didn't observed in $2.2 \mathrm{wt} . \%$ alloy cooling curve, while it observed for two other alloys. Copper content increment from 2.2 to $4.8 \mathrm{wt} \%$ caused to increment non-equilibrium eutectic amount from 2.3 to $5.7 \mathrm{wt} . \%$ (see Table 2 ), that increases the solidification latent heat. In order to more precious investigate on the effect of chemical composition on the latent heat due to non-equilibrium eutectic transformation, a part of derivative - time curves in $0.42{ }^{\circ} \mathrm{C} / \mathrm{s}$ cooling rate for all three 
alloys, is shown in Fig. 10. With comparison of these curves, it is well perceived that in a constant cooling rate, with copper content increment, latent heat also increases, which this increment in latent heat is well recognized from the comparison of depicted peaks in first derivative curves. Actually, the start point for increments in first differential amounts (with respect to the sign) is indicant of non-equilibrium eutectic transformation start which accompanies with latent heat loose. Loosed latent heat causes to sample temperature raise and cooling rate decrement. Hereafter, the cooling rates gets the minimum value (point $b$ ). With transformation termination, the cooling rate increases again until the alloy solidification is finished (point c).

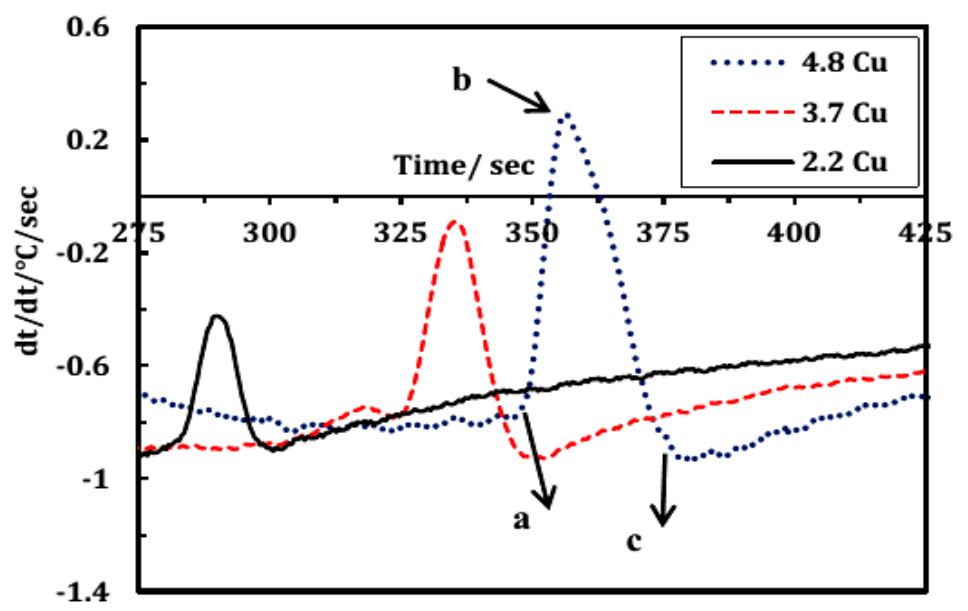

Figure 10. A part of first derivative - time curves in $0.42^{\circ} \mathrm{C} / \mathrm{s}$ cooling rate for alloys.

\section{Conclusions}

In this investigation, the effect of cooling and chemical composition on the nonequilibrium eutectic formation during the solidification of aluminum-copper alloys was studied by means of cooling curves thermal analysis. A summary of most important results are given below:

1. Loosed latent heat during non-equilibrium eutectic transformation is dependent two factors: a: chemical composition b: cooling rate.

2. In very low cooling rates for $2.2 \mathrm{wt} . \%$ alloy, non-equilibrium eutectic forms in final structure, but the amount of loosed latent heat due to its formation is too low that its distinction from cooling curves is hard and needs to plot the derivative-time curves.

3. With cooling rate increment from 0.04 to $0.42{ }^{\circ} \mathrm{C} / \mathrm{s}$ and copper content increment from 2.2 to $4.8 \mathrm{wt} . \%$, the amount of non-equilibrium eutectic increased from 2.3 to 5.7 wt.\% which accompanies with latent heat increment.

4. With comparison of third peaks in derivative -time curves, can be able to investigate the variation of non-equilibrium eutectic with cooling rate and copper content variation, qualitatively. 


\section{References}

[1] MC. Flemings, USA; MacGrraw-Hill, (1974) 341-344.

[2] D. Eskin, Q. Du, D. Ruvalcaba, L. Katgerman. Mater Sci Eng A. 405 (2005) 1-10.

[3] S.L Backerud, G.K. Sigworth, AFS Trans.97 (1989) 459-464.

[4] M. Dehnavi, H. Vafaeenezhad, M. Haddad - Sabzevar, Metall Mater Eng. 20 (2014) 107-117.

[5] W.T. Kierkus, J.H. Sokolowski, AFS Trans, 66 (1999)161- 167.

[6] D. Emadi, L.V. Whiting, S. Nafisi, R. Ghomashchi, J Therm Anal Calorim, 81 (2005) 235-42

[7] S.M. Liang, R.S. Chen, J.J Blandin, M. Suery, E.H. Han, Mater Sci Eng A. 480 (2008) 365-372.

[8] K.G. Upadhya, D.M. Stefanescu, K. Lieu, D.P. Yeager. AFS Trans, 97 (1989) 616.

[9] O. Fornaro, H.A. Palacio. J Mater Sci, 44, (2009) 4342-4347.

[10] D. Emadi, L. Whiting, M. Djurdjevic, W.T. kierkus, J.H. sokolowski, Metall Mater Eng. (2004) 91-106.

[11] Ihsan-ul-haq, J.S. Shin, Z.H. Lee, Met Mater Int, 10 (2004) 89-96.

[12] H. Morrogh, W.J Williams. Journal of Iron and Steel Institute, (1954)375-378.

[13] A. Hultgran, Y. Lindblom, E. Rudberg, Journal of Iron and Steel Institute, (1954) 365-374.

[14] L. Bäckerud, B. Chalmers, Transactions of the Metallurgical Society of AIME, 245 (1969) 309-318.

[15] L.A. Dobrzanski, R. Maniara, J. Sokołowski, W. Kasprzak. J Mater Process Technol, 191 (2007) 317-20.

[16] S.G. Shabestari, S. Ghodrat, Mater Sci Eng A,467 (2007) 150-8.

[17] M. Dehnavi, M. Haddad -Sabzevar. Master Thesis, Ferdowsi University of Mashhad, (2013).

[18] ASM Hnadbook, Formerly Ninth Edition, Metals Hnadbook, Volume 9, Metallography and microstructures. 